\title{
La teoría de la infracción ambiental en Colombia desde una concepción funcionalista del derecho penal
}

\section{The theory of environmental violation in Colombia from the criminal law point of view}

\author{
JESÚS MARÍA ACEVEDO MAGALDI \\ Abogado, especialista en derecho y gestión ambiental, especialista en derecho penal, Magister en derecho administrati- \\ vo, docente de la Universidad Autónoma del Caribe. \\ Jesusacevedomagaldi@hotmail.com
}

Recibido: Septiembre 16 de 2013

Aceptado: Noviembre 13 de 2013

\begin{abstract}
En la legislación moderna se entiende que el medio ambiente es un derecho al que deben tener acceso todos los asociados y que la encargada de velar por su protección es la Administración pública, vigilando, corrigiendo y sancionando las actividades y/o a los particulares causantes de daños ambientales, hecho constitucionalmente reconocido, cabe resaltar que esta labor sería ineficaz si no se cuenta con la participación activa de la ciudadanía, de la misma manera, la ineficiente o irresponsable participación de la Administración en la actividad social y económica mediante la prestación de servicios públicos, puede incidir y ocasionar daños sobre los recursos naturales y sobre el medio ambiente en general. Sin embargo pese a existir una normatividad en materia de protección del medio ambiente y unas autoridades constituidas para ello a través de la ley 99 de 1993 que creó el sistema nacional ambiental, y más aún, existiendo un proceso sancionatorio ambiental contenido en la ley 1333 de 2009 no se la ha brindado la importancia suficiente al desarrollo de los elementos constitutivos de la infracción ambiental. En este artículo de reflexión se muestra como a diferencia de otras disciplinas del derecho como lo es el derecho penal, el derecho ambiental se ha visto rezagado en el diseño eficiente de una metodología jurídica para la determinación de responsabilidad ambiental y de la comisión de la infracción que viene a ser la columna vertebral de la motivación del acto administrativo sancionatorio, por lo que se hace importante la determinación de una estructura de la infracción en materia ambiental que permita a la administración no cometer injusticias, pero que tampoco permita los administrados transgredir los derechos colectivos y del ambiente.

Palabras clave: Medio ambiente, teoría del delito, infracción ambiental, sanción, acto administrativo, autoridades ambientales

ABSTRACT

In modern legislation, it is understood that the environment is a right to which all people must have access and the public Administration has to guard over his protection, monitoring, correcting and sanctioning the activities or to the causative individuals of environmental damages. It is necessary to highlight that this labor would be ineffective if one does not possess the active participation of the citizenship. In addition, the inefficient or irresponsible participation of the Administration in the social and economic activity by means of the provision of public services can affect and cause damage on the natural resources and on the environment in general. In this article, it is shown the environmental right latecomer has met in the efficient design of a juridical methodology for the determination of environmental responsibility and of the commission of the infraction that comes to be the vertebral column of the motivation of the administrative act, by what there becomes important the determination of a structure of the infraction in environmental matter that allows the administration not to commit injustices, and does not allow the administered ones to transgress the collective rights.

Keywords: Environment, theory of the crime, environmental infraction, sanction, administrative act, environmental authorities.
\end{abstract}


Colombia no es ajena al advenimiento de las políticas globales, por tal razón se ha visto obligada a implementar cambios en sus políticas gubernamentales, consecuencia de ello los retos de la administración pública se han venido transformando, dándole mayor importancia a temas de carácter social, de tal manera que no solo se hace necesario realizar una gestión a nivel administrativa para el presente, sino que deberá desarrollarse una gestión que procure perdurar en el tiempo y que permita que nuevas generaciones y futuros ciudadanos se beneficien de estas.

Es el medio ambiente; uno de los más importantes ejes temáticos de la actualidad en todos los niveles; ya sea administrativo, educativo, empresarial, y gubernamental, en virtud de la importancia de su conservación y adecuado manejo que permita la preservación de la especie humana y la mejora de las condiciones de vida de la población actual; y es por ello que cualquier acción que se tome en dicha materia, genera unas consecuencias e impactos de los cuales la administración pública se vuelve garante y rectora fundamental de ello, a tal punto que las obligaciones jurídicas que la Constitución impone al Estado y a los particulares para proteger el medio ambiente, guardan una estrecha relación con lo dispuesto en los artículos 1 y 2 de la Carta, conforme a los cuales, por un lado, se afirma que Colombia es un Estado Social de Derecho que se funda, entre otros, en la prevalencia del interés general, y, por otro, se dispone que el Estado debe garantizar la efectividad de los principios, derechos y obligaciones consagrados en la norma superior.

En la legislación moderna se entiende que el medio ambiente es un derecho al que deben tener acceso todos los asociados y que la encargada de velar por su protección es la Administración pública, vigilando, corrigiendo y sancionando las actividades o a los particulares causantes de daños ambientales, hecho constitucionalmente reconocido, cabe resaltar que esta labor sería ineficaz si no se cuenta con la participación activa de la ciudadanía, de la misma manera, la ineficiente o irresponsable participación de la Administración en la actividad social y económica mediante la prestación de servicios públicos, puede incidir y ocasionar daños sobre los recursos naturales y sobre el medio ambiente en general, sin embargo pese a existir una normatividad en materia de protección del medio ambiente y unas autoridades constituidas para ellos a través de la ley 99 de 1993 que creó el sistema nacional ambiental, y más aún, existiendo un proceso sancionatorio ambiental contenido en la ley 1333 de 2009 no se la ha brindado la importancia suficiente al desarrollo de los elementos constitutivos de la infracción ambiental.

A diferencia de otras disciplinas del derecho como lo es el derecho penal, el derecho ambiental se ha visto reza- gado en el diseño eficiente de una metodología jurídica para la determinación de responsabilidad ambiental y de la comisión de la infracción que viene a ser la columna vertebral de la motivación del acto administrativo sancionatorio, por lo que se hace importante la determinación de una estructura de la infracción en materia ambiental que permita a la administración no cometer injusticias, pero que tampoco permita los administrados transgredir los derechos colectivos y del ambiente.

Las medidas administrativas constituyen la manera como las autoridades que tienen a cargo el cuidado del medio ambiente y la gestión de los recursos naturales, adoptan decisiones sobre preservación, conservación, uso y aprovechamiento sostenible utilizando las prerrogativas de que disponen; entre ellas, el ejercicio de la potestad sancionatoria, que ha sido la herramienta de común utilización para cumplir con el mandato superior de la protección ambiental.

A pesar de existir la facultad sancionatoria en materia ambiental por parte de la administración, se entiende que dicha actuación debe revestir carácter preventivo, pues el ideal es evitar atentados contra el ambiente, De allí que la acción de la autoridad ambiental, para que sea acertada, no solo debe contemplar acciones sancionatorias y represivas; lo ideal es que se ejerza precaviendo transgresiones al entorno y en consenso con los demás agentes regulados; mas allá, el Estado siempre tiene y tendrá en el ius puniendi administrativo, una herramienta a la cual puede recurrir para soslayar la falta de concienciación colectiva frente a la problemática ambiental. En palabras del tratadista Español Ramón Martin Mateo: "Las medidas represivas, aunque inevitable correlato de otras estrategias, han se suponer una aportación sólo excepcional a una eficaz disciplina ambiental" (Mateo, 1997. P.98)

Ahora bien, dada la existencia de la potestad sancionatoria del estado Colombiano en materia ambiental, el problema actual que se tiene es que la ley 1333 de 2009 a través de la cual se establece el procedimiento sancionatorio en materia ambiental, carece de una estructura de la infracción, toda vez que a diferencia del derecho penal, se adolece totalmente de un criterio sano y metódico de la imposición de la infracción en materia ambiental por parte del operador administrativo ambiental.

Se debe resaltar que Colombia es un Estado Social de derecho, y al ser un estado donde imperan las normas, debe ser también un estado donde se garantice que los poderes exorbitantes de la administración no perjudiquen a un ciudadano de forma injustificada e ilegal, o que tenga que cargar con cargas más pesadas que las que está obligado por mandato legal, haciendo referencia a la teoría de las 
cargas públicas ya bien decantada por el máximo órgano constitucional, por lo que en materia de imposición de sanciones por la comisión de infracciones a la normatividad ambiental vigente aún no se ha desarrollado una esquemática seria y profunda para ello.

Los operadores administrativos de las autoridades ambientales, en su gran mayoría, adolecen de un plan metodológico para efectos de motivación del acto administrativo sancionatorio, por lo que solamente toman como referente el hecho, la presunción de culpa o dolo y el sujeto, desconociendo elementos desarrollados en la dogmática del delito en materia penal, que bien se pueden utilizar en la infracción ambiental como la antijuridicidad, la tipicidad, la necesidad de la pena, la imputabilidad y demás elementos constitutivos del delito.

Es cierto, que el derecho penal es una disciplina autónoma e independiente a cualquier otra, toda vez que su objeto de estudio, y sus titulares son distintos a cualquier otro, sin embargo el hecho de que sea autónomo no excluye que los desarrollos dogmáticos realizados a través de la historia por autores tan importantes como Roxin, Weber, Welzel, Zafarroni, Kelsen, y demás eminencias del derecho moderno, no puedan ser utilizadas en otras disciplinas jurídicas como el derecho ambiental, toda vez que entre el derecho penal y el derecho ambiental son más las similitudes que las diferencias, al punto que el estado es titular de la acción en ambos casos, que como conclusión procesal se determina la existencia de responsabilidad o ausencia de esta, y que además en ambos casos existe una sanción o pena.

Es pues importante brindar a los estudiosos del derecho ambiental, operadores administrativos y comunidad académica en general, una teoría seria para la determinación de la responsabilidad y la imposición de una sanción en materia ambiental, y como no, partiendo de estudios sobre la teoría del delito, y tomando los elementos desarrollados en dichas teorías que se puedan ajustar al derecho ambiental sin desconocer su autonomía y sus diferencias $\mathrm{y} \sin$ atentar contra su esencia administrativa.

La teoría del delito es un sistema de categorización por niveles, conformado por el estudio de los presupuestos jurídico-penales de carácter general que deben concurrir para establecer la existencia de un delito, es decir, permite resolver cuando un hecho es calificable de delito.

Esta teoría, creación de la doctrina, pero basada en ciertos preceptos legales, no se ocupa de los elementos o requisitos específicos de un delito en particular (homicidio, robo, violación, etc.), sino de los elementos o condiciones básicas y comunes a todos los delitos.
Se da por sentado que la Teoría del Delito nos enseña los diferentes niveles del análisis que deben resolver de forma integrada el estudio de la conducta humana para calificarla como "delito", está claro que esa caracterización obliga a una ordenada segregación de "hechos" que una vez convertidos en "tipos" descritos e individualizados por la ley deberán ser sancionados como prescribe la norma en el entendido de que se trata de conductas prohibidas. (Nieves, 2010)

Este universo complejo de conducta - acción delictiva resultado - reproche (sanción) es la materia prima de la que se nutre la Teoría Jurídica del Delito, y, en esencia, la dogmática penal.

Al dimensionar y dar trascendencia a la acción humana que se convierte en conducta típica por no estar autorizada por la ley, la dogmática se alza como rectora de este encabritado ejercicio del saber penal que, a buen seguir, es el ungüento por excelencia para tales fines.

Históricamente, se puede hablar de dos corrientes o líneas: la teoría causalista del delito y la teoría finalista del delito. Para la explicación causal del delito la acción es un movimiento voluntario físico o mecánico, que produce un resultado el cual es tomado por el tipo penal, sin tener en cuenta la finalidad de tal conducta. La teoría finalista del delito entiende la conducta como un hacer voluntario final, en cuyo análisis deben considerarse los aspectos referidos a la manifestación exterior de esa finalidad. La primera corriente considera preponderantemente los elementos referidos al desvalor del resultado; la segunda, por el contrario, pone mayor énfasis, en el desvalor de la acción. Más recientemente, la teoría funcionalista intenta constituir un punto de encuentro entre finalistas y causalitas, destacando en esta línea Claus Roxin en Alemania y Paz de la Cuesta en España, entre otros. (Nieves, 2010)

En este orden de ideas, cuando se habla de la teoría del delito, ineludiblemente se debe de hablar de la existencia, ponderación y análisis de los elementos constitutivo del delito entre una y otra teoría, a saber:

\section{La teoría causalista}

Fundada por Frank Von Liszt (1930), hace un análisis sistemático del Derecho Penal y del Delito, partiendo de una explicación naturalística de la acción humana desde la cual se genera el delito. La acción se entendía como el impulso de la voluntad, generadora de un movimiento corporal que supone la causación de un resultado (Nieves, 2010). 
El delito comprende una acción ejecutada (acción stricto sensu) de una parte; y una acción esperada (omisión) de otra parte; así como un resultado sobrevenido.

Para que el delito pueda ser sancionado precisa de la existencia de un nexo causal o una relación de causalidad entre el acto humano y el resultado producido: "existe una relación causal cuando no se puede suponer suprimido el acto de voluntad humana, sin que deje de producirse el resultado concreto, el resultado debe ser causado (provocado) por un movimiento corporal; el movimiento corporal y el resultado deben estar en relación de causa a efecto una relación de causalidad" ${ }^{\prime 1}$

En esta teoría, se fundamenta en el principio de la causalidad natural: todo resultado es producto de una causa, teniéndose entonces que valorar la causa, el nexo causal, y el efecto

En este mismo orden de ideas encontramos como segundo elemento del delito: La Tipicidad. Esta es una valiosa aportación del causalismo a la teoría general del delito; porque la tipicidad se convierte en fundamento de la sistematización del hecho punible, y además, en garantía de libertad, que sirve al juez como marco de referencia preciso, para evitar la aplicación analógica y caprichosa del derecho penal.

El Causalismo en un principio definió la antijuricidad como lo contrario al derecho, no obstante, Jiménez de Asúa, enmienda ese error y establece que "La persona que comete un delito no hace lo contrario a la ley, sino que, precisamente, su conducta se ajusta a lo prescrito por la ley en el tipo". Por lo que es antijurídica aquella conducta que contradice las normas de cultura reconocidas por el Estado.

Siguiendo con los elementos constitutivos del delito, la culpabilidad es para los causalistas, una síntesis sobre la base de relaciones naturalísticas. Es una relación psicológica entre el sujeto y el acto, el acto se integra, en la teoría causal del delito de: conducta, resultado y nexo causal, y la conducta a su vez la componen un elemento psíquico y otro físico, el primero es la voluntariedad de la propia conducta y en el segundo se proyecta el elemento psíquico de la actividad o inactividad humana (Nieves, 2010. P.7)

\section{El finalismo}

Esta teoría fue desarrollada por Hans Welzel (1987). en Alemania en el año1930 y básicamente critica al Causalismo y

\footnotetext{
Liszt, definía como una inervación muscular la producida por la energía de un impulso cerebral, por un medio natural (leyes causales de la naturaleza) y que provoca una mutación o cambio en el exterior, perceptible por los sentidos.
}

lo acusa de erróneo porque desconoce "las diferencias positivas entre delitos culposos y los dolosos".

El que asesina a otro está condicionado causalmente, selecciona los factores causales conscientemente, pero los dispone de forma tal que alcance la meta predeterminada: seleccionar el arma, la ocasión propicia, se sitúa al acecho, apunta el arma, dispara... todos ellos, son actos dirigidos a la meta, sometidos a un plan conjunto.

El pensamiento finalista de Welzel arranca de la ética kantiana y de la filosofía de Nicolai Hartmann. "El fin es a la voluntad como el valor al deber ser". "Sólo el sujeto es capaz de proponerse fines, es decir, de transformar los valores que ha intuido en metas de su acción" En la acción dolosa de la finalidad la meta y el fin a conseguir es factor configurado del proceso de acción.

En la acción culposa sólo es un momento de referencia. En la acción dolosa todos los actos van dirigidos a una meta; en la culposa no; sin embargo, cualquier acción culposa, no dirigida hacia una meta, sino que sea "causa ciega", adquiere, más que un rasgo natural, la circunstancia de ser evitable finalmente. Es decir, el hecho de ser evitable, le concede el carácter de ser más que un hecho fortuito ciego, es una genuina acción. ${ }^{2}$

En cuanto al tipo y la tipicidad, sostiene Muñoz Conde (1990) que en estos se encuentra la característica fundamental del finalismo: "la acción u omisión humanas subsumibles en el tipo, no son simples procesos causales ciegos, sino procesos causales regidos por la voluntad". Es de esta manifestación que el finalismo da preponderancia a los elementos del tipo subjetivo, en donde ubican en la tipicidad, precisamente al Dolo y la Culpa.

Ahora bien, habiendo recorrido muy brevemente estas dos corrientes teóricas del delito, se hace necesario establecer de forma metódica, cuales vendrían a ser los elementos constitutivos del delito y a su vez analizar cuales se podrían aplicar a la teoría de la infracción en materia ambiental a luz de la teoría funcionalista expuesta por Roxín (1976) para quien la dogmática no debe sustentarse exclusivamente en desarrollos lógicos y normativos, sino que tiene que atender a la realidad social y ofrecer soluciones conforme a los conocimientos ofrecidos por la política criminal.

Frente a esta teoría expuesta por Roxín, se encuentra dos innovaciones centrales del funcionalismo para dar un cambio casi copernicano a la teoría del delito: la teoría de la imputación al tipo objetivo y la tercera categoría de la

Ibídem 
teoría del delito, denominada responsabilidad, la cual se compone de la culpabilidad y la necesidad de imponer la pena.

Como primer elemento de la teoría Funcionalista sobre la cual se soportará la teoría de la infracción ambiental, encontramos;

La conducta: El sistema funcionalista rechaza las concepciones de la conducta ofrecidas por los anteriores sistemas, debido a que la formación del sistema jurídico penal no puede vincularse a las realidades ontológicas previas (acción, causalidad, estructuras lógico reales, etcétera), sino que única y exclusivamente puede guiarse por finalidades del derecho penal. A esto se debe sumar que un concepto de conducta como control de cursos causales dirigido a un determinado objetivo no sustenta satisfactoriamente ni la culpa ni la omisión. La identidad del aspecto voluntario: un hombre habrá actuado si determinados efectos procedentes o no del mismo se le pueden atribuir a él como persona, o sea como centro espiritual de acción, por lo que se puede hablar de un hacer o dejar de hacer y con ello una manifestación de la personalidad. ${ }^{3}$

En materia ambiental la conducta juega un papel preponderante que debe ser analizada de manera juiciosa por el operador administrativo, teniendo en cuenta que uno de los aspectos más relevantes es la atribuidibilidad de la conducta a un determinado sujeto.

Ahora bien, como premisa fundamental del inicio de una actuación administrativa y por ende de la motivación del acto administrativo a través del cual se inicia un procedimiento sancionatorio ambiental, es la plena identificación del sujeto a quien se le atribuirá la conducta de hacer o dejar de hacer, en este caso de acción y de omisión.

La Tipicidad: La teoría funcionalista interpreta las conductas descritas en los tipos penales en función de la necesidad abstracta de la pena para un supuesto regular y no basado en la personalidad del sujeto en concreto o de la concreta situación de la actuación. Al tipo se le confiere la función de llamada, no solo capta o describe simples procesos causales naturales, pues tiene como función enviar un mensaje al raciocinio del individuo para que sepa cuáles son las conductas prohibidas con el fin político criminal de que las evite (delitos de acción), o bien, realice la conducta ordenada para la salvaguarda de un bien jurídico en peligro (delitos de omisión).

Recuperado de internet disponible en http:/ / penaldelito.blogspot. com/2009/10/teoria-causalista-finalista.html
Para persuadir al individuo, el tipo establece una pena a imponer a quien contravenga el mensaje y de esa forma se busca disuadirlo o causarle temor para que se abstenga de realizar la conducta que lesiona el bien jurídico tutelado o actué para evitar la lesión de ese bien, el efecto disuasorio se conoce como prevención general negativa, y obedece a los lineamientos generales de un derecho penal preventivo general. El tipo penal describe una conducta, pero la realidad ofrece multiplicidad de conductas que podrían adecuarse a dicha descripción, luego entonces se debe determinar cuáles de esas conductas se han pretendido prevenir a través del tipo. Solo aquellas conductas así identificadas pueden ser consideradas como desaprobadas legalmente y en consecuencia, son típicas. ${ }^{4}$

Cuando se revisa la teoría de la infracción ambiental, se tiene que guarda estrecha similitud con la necesidad de tipificación en materia penal, esto como mecanismo de seguridad jurídica y de garantía constitucional al debido proceso.

La descripción de la infracción ambiental, al igual que el derecho penal, debe estar como requisito fundamental, típicamente descrita en el ordenamiento jurídico positivo, por lo que en este régimen debe estar proscrita la posibilidad de imposición de sanciones de carácter ambiental bajo postulados de tipos abiertos o en blanco o mejor llamados numerus apertus ${ }^{5}$

Ahora bien, la descripción de la conducta conminada a desplegar, a diferencia del derecho penal, no siempre es negativa, si no que por el contrario generalmente es positiva, y llamada al cumplimiento de deberes, con verbos o acciones como cuidar, preservar, presentar, cumplir, garantizar, etc.

Sin embargo en este sentido, las normas sancionatorias ambientales establecen lo que se conoce como tipificación indirecta que presupone la existencia de un precepto que establece un mandato, una prohibición y otro que establece que el incumplimiento de éstos será objeto de sanción. (Garra y Arroyave, 2011)

\footnotetext{
Ibídem

El legislador en ejercicio de su facultad de configuración también ha adoptado un sistema amplio y genérico de incriminación que ha sido denominado "numerus apertus", en virtud del cual no se señalan específicamente cuales comportamientos requieren para su tipificación ser cometidos con culpa -como sí lo hace la ley penal-, de modo que en principio a toda modalidad dolosa de una falta disciplinaria le corresponderá una de carácter culposo, salvo que sea imposible admitir que el hecho se cometió culposamente como cuando en el tipo se utilizan expresiones tales como "a sabiendas", "de mala fe", "con la intención de" etc. Por tal razón, el sistema de numerus apertus supone igualmente que el fallador es quien debe establecer cuales tipos disciplinarios admiten la modalidad culposa partiendo de la estructura del tipo, del bien tutelado o del significado de la prohibición.
} 
Por consiguiente, la infracción la constituye el incumplimiento de las normas contenidas en una reglamentación específica. Así lo establece el artículo $5^{\circ}$ de la Ley 1333 de 2009, al definir como infracción ambiental la comisión de un daño al medioambiente que reúna las características allí mencionadas y que también lo es "toda acción u omisión que constituye violación de las normas contenidas en el Código de Recurso Naturales Renovables, en la Ley 99 de 1993, en la Ley 165 de 1994 y en las demás disposiciones ambientales vigentes".

La Antijuridicidad: Para Roxin (1976) una acción es formalmente jurídica en la medida en que contraviene una prohibición o mandato legal, y es materialmente antijurídica en la medida en que en ella se plasma una lesión de bienes jurídicos socialmente nociva y que no se puede combatir suficientemente con medios extrapenales.

Por otra parte, Cabanellas expresa que es

...Toda manifestación, actitud o hecho que contraría los principios básicos del Derecho. En orden menor, lo contrario al Derecho Positivo. Específicamente, elemento esencial del delito, cuya fórmula es el valor que se concede al fin perseguido por la acción criminal contra el garantizado por el Derecho. (Cabanellas, G. 1986. P.310)

Por consecuencia de la definición expuesta, lo antijurídico será aquello que se realiza en contradicción al Derecho, en contraposición a lo que dispone la ley; y en el evento que estamos tratando, a pesar de que se produce la conducta y el acto típicos, no se ha violado la ley, porque ella misma faculta cometer dicho acto.

En este orden de ideas, y aterrizando el tema a nuestro objeto de estudio, la antijuridicidad en materia ambiental se podría confundir con el concepto de tipicidad, los cuales deben ser entendidos como dos niveles de valoración de la conducta diferenciados e independientes.

La tipicidad debe ser entendida como el juicio que expresa la relevancia penal específica de una conducta con carácter general, y, por lo tanto, como el conjunto de los elementos que fundamentan lo injusto penal específico de la conducta punible. La antijuridicidad, en cambio, es el juicio que expresa la contradicción de una conducta típica con la totalidad del ordenamiento jurídico. La antijuridicidad es un concepto unitario y válido para todo el ordenamiento jurídico, de tal modo que lo que es antijurídico en una rama del Derecho lo es también en las restantes.

Una conducta típica es generalmente antijurídica, pero puede no serlo en el caso concreto si concurre alguna causa de justificación. Según esto, la tipicidad supone un juicio de antijuridicidad provisional, mientras que la ausencia de causas de justificación fundamenta ya un juicio de antijuridicidad definitivo sobre la conducta. Esta concepción supone un rechazo de la teoría de los elementos negativos del tipo. De acuerdo con esta teoría la distinción entre tipicidad y antijuridicidad es meramente nominal, pues la ausencia de los presupuestos objetivos de una causa de justificación serían elementos negativos del tipo.

De acuerdo con esta concepción, de las prohibiciones y de los mandatos se derivan, los tipos de injusto que expresan una desaprobación jurídico penal específico de la conducta con carácter general. De las normas permisivas se derivan, en cambio, tipos de causas de justificación, que describen circunstancias en que el ordenamiento jurídico autoriza a realizar una conducta típica en el caso concreto.

Ahora bien, la ley 1333 de 2009, trae consigo solo dos causales de eximentes de responsabilidad a saber;

Son eximentes de responsabilidad:

1. Los eventos de fuerza mayor o caso fortuito, de conformidad con la definición de los mismos contenida en la Ley 95 de 1890.

2. El hecho de un tercero, sabotaje o acto terrorista.

Revisando la causal primera de la precitada norma debemos por analogía remitirnos al artículo 64 del código Civil Colombiano que reza que;

...Se llama fuerza mayor o caso fortuito el imprevisto o que no es posible resistir, como un naufragio, un terremoto, el apresamiento de enemigos, los actos de autoridad ejercidos por un funcionario público, etc.

Entendido lo anterior, es menester expresar que revisando los elementos del tipo y de la antijuridicidad para la imposición de la sanción administrativa ambiental se debe atender a los preceptos normativos ambientales, y el concepto de norma ambiental que en ultimas acapararíamos a la obligación de hacer o no hacer y que podrá ser sujeto de persecución administrativa por las autoridades ambientales a través de un proceso sancionatorio ambiental.

En este sentido se debe expresar que el concepto de infracción ambiental es distinto al concepto de norma ambiental toda vez que a diferencia del derecho penal, las infracciones ambientales no se encuentra en un compendio normativo que contenga la descripción típica de la conducta, sino que por el contrario debemos remitirnos a la norma cuya única descripción típica 
está contenida en el artículo $5^{\circ}$ de la ley 1333 de 2009 y que trae consigo la expresión "Se considera infracción en materia ambiental toda acción u omisión que constituya violación de las normas". Es justamente partiendo de esta definición legal, es muy sencillo encuadrar el tipo y la antijuridicidad ya que estos solo harán referencia al "cumplir" o "incumplir" con la normatividad ambiental vigente lo cual en términos penales sería algo totalmente proscrito por el constituyente en el artículo 29 de la constitución.

Ahora bien, el concepto de norma ambiental aunque se encuentra contenido en el artículo $5^{\circ}$ de la ley 1333 de 2009, presupone una dualidad o vacío jurídico para efectos de brindar una seguridad legal al procesado y a la misma autoridad ambiental ene le momento de expedir los actos administrativos sancionatorios o en el marco de la expedición de actos procesales.

Se entienden como normas ambientales según el artículo precitado

...las normas contenidas en el Código de Recursos Naturales Renovables, Decreto-ley 2811 de 1974, en la Ley 99 de 1993, en la Ley 165 de 1994 y en las demás disposiciones ambientales vigentes en que las sustituyan o modifiquen y en los actos administrativos emanados de la autoridad ambiental competente

Sin embargo es evidente que en el marco de la hiperinflación normativa Colombiana y la constante actividad legislativa, esta definición precitada y contenida en la ley 1333 de 2009, deja por fuera las posibilidades futuras a las leyes que se expidan sobre la materia, o que regulen la utilización, manejo, y aprovechamiento de los recursos naturales.

Es evidente que la definición de normas ambientales creada por el legislados carece de técnica jurídica y no mantuvo el espíritu previsivo y futurista que debe tener la ley, ya que solo limita el concepto de norma ambiental a las reformas y sustituciones que pueda sufrir el Código de Recursos Naturales Renovables, Decreto-ley 2811 de 1974, la Ley 99 de 1993, y la Ley 165 de 1994.

Ahora bien, a diferencia del tema penal, esta definición que hace referencia a "los actos administrativos emanados de la autoridad ambiental competente" deja abierta la puerta a la posibilidad de reglamentación y de expedición de actos administrativos que regulen la materia o que en su defecto impongan obligaciones ambientales concretas a un sujeto especifico, como es el caso de imposición de obligaciones, planes de manejo ambiental o licencias ambientales que en últimas son solo exigibles al destinatario del acto administrativo particular.
Responsabilidad: La culpabilidad, como cuarta categoría de la teoría del delito es sustituida por Roxin (1976) por la responsabilidad la cual se conforma por la culpabilidad y la necesidad de la pena, la categoría de la responsabilidad tiene que resolver el problema de determinar bajo que presupuestos el autor puede ser penalmente responsable por un injusto realizado.

El sujeto actúa culpablemente cuando realiza un injusto jurídico-penal pese a que (todavía) le podía alcanzar el efecto de llamada de atención de la norma en la situación concreta y poseía una capacidad suficiente de autocontrol. No obstante para considerar responsable al sujeto, además de la culpabilidad, se debe constatar la necesidad de imponerle la pena y no una sanción menos nociva, para lo cual es necesario acudir a los fines de la pena.

En este punto, no podemos olvidar el carácter de la norma ambiental, se consagra en el artículo $5^{\circ}$ de la ley 1333 de 2009 que expresa:

...Será también constitutivo de infracción ambiental la comisión de un daño al medio ambiente, con las mismas condiciones que para configurar la responsabilidad civil extracontractual establece el Código Civil y la legislación complementaria, a saber: El daño, el hecho generador con culpa o dolo y el vínculo causal entre los dos. Cuando estos elementos se configuren darán lugar a una sanción administrativa ambiental, sin perjuicio de la responsabilidad que para terceros pueda generar el hecho en materia civil.

Sin embargo, es menester resaltar también lo consignado en el parágrafo único del artículo $1^{\circ}$ de la misma norma el cual expone:

...En materia ambiental, se presume la culpa o el dolo del infractor, lo cual dará lugar a las medidas preventivas. El infractor será sancionado definitivamente si no desvirtúa la presunción de culpa o dolo para lo cual tendrá la carga de la prueba y podrá utilizar todos los medios probatorios legales.

Es pues en este punto de partida que se debe de analizar la responsabilidad en materia ambiental, toda vez que la carga de la prueba está en cabeza del investigado, lo cual es una diferencia sustancial con la ley penal, mas sin embargo, esta carga probatoria ha sido mal entendida por las autoridades ambientales toda vez, que aunque no tienen según la ley la carga demostrativa, si poseen bajo la acepción de autoridad administrativa, el deber legal y constitucional de motivar sus actos administrativos, por lo que la precitada norma no puede ser óbice de capricho 
o arbitrariedad de la administración, sino por el contrario se deberá entender como la posibilidad material de defensa en cabeza del investigado.

Frente a la motivación del acto administrativo, ha dicho el Consejo de estado en sentencia del 10 de abril de 2008, expediente 15204:

Ahora bien, el artículo 35 del Código Contencioso Administrativo dispone que los actos administrativos deban estar motivados al menos en forma sumaria. Lo que se busca con la motivación del acto es asegurarle al administrado que la decisión que tome la Administración obedezca a las razones de hecho y de derecho que ésta invoca, de tal forma que la motivación se hace imprescindible para dictar los actos administrativos, y expedirlos sin la misma, implica un abuso en el ejercicio de la autoridad y necesariamente responsabilidad de quien ha omitido tal deber. Correlativamente, la motivación del acto permite al administrado rebatir $u$ oponerse a las razones que tuvo en cuenta la autoridad para tomar su decisión. Lo sumario de la motivación, no puede confundirse con insuficiencia o superficialidad, pues, ésta alude a la extensión del argumento y no a su falta de contenido sustancial; luego, el señalamiento de los motivos en que el acto encuentra soporte, no por sumario debe ser incompleto y, menos, inexistente. La motivación es un requisito esencial del acto y debe basarse en hechos ciertos y demostrados al momento de la expedición del mismo, so pena de nulidad, por ausencia de uno de sus elementos esenciales.

Conforme a lo anterior cualquier acto administrativo ya sea procesal o definitivo en el marco de un proceso sancionatorio ambiental debe poseer una correcta motivación toda vez que esta necesaria para garantizar el derecho a la defensa del presunto infractor, puesto que si la autoridad administrativa ambiental no explica adecuadamente de qué se trata su acusación, el procesado no podrá defenderse adecuadamente en la medida en que no conoce a ciencia cierta de qué es lo que se le acusa o que se le endilga, ni mucho menos podrá controvertir de forma adecuada las pruebas que se tengan en su contra.

\section{Sobre la caducidad de la acción administrativa ambiental}

Antes de iniciar una adecuación de los elementos aquí descritos de la infracción en materia ambiental, el operador administrativo ambiental, deberá hacer un análisis juicioso sobre la posibilidad de perseguir, investigar e imponer una sanción administrativa de carácter ambiental, por lo que debe de remitirse al primer elemento como lo es la caducidad de la acción del estado.

Frente a esto es importante resaltar que en palabras de la corte constitucional en sentencia C- 401 de $2010 \mathrm{La}$ caducidad es una institución jurídico procesal a través de la cual, el legislador, en uso de su potestad de configuración normativa, limita en el tiempo el derecho que tiene toda persona de acceder a la jurisdicción con el fin de obtener pronta y cumplida justicia, y su fundamento se halla en la necesidad que tiene el conglomerado social de obtener seguridad jurídica, para evitar la paralización del tráfico jurídico." ${ }^{6}$

La prescripción es entonces, un instituto jurídico liberador, en virtud del cual por el transcurso del tiempo se extingue la acción o cesa el derecho del Estado a imponer una sanción, y ocurre cuando quienes tienen a su cargo el ejercicio de la acción penal dejan vencer el plazo señalado por el legislador para el efecto sin haber adelantado las gestiones necesarias tendientes a determinar la responsabilidad del infractor de la ley penal, lo que implica que la autoridad judicial competente pierde la potestad de seguir una investigación en contra de la persona beneficiada con la prescripción, y su fundamento se encuentra en el principio de la seguridad jurídica. La prescripción de la acción penal tiene una doble connotación: por un lado, obra a favor del procesado, quien se beneficia de la garantía constitucional que le asiste a todo ciudadano para que se le defina su situación jurídica, pues no puede quedar sujeto perennemente a la imputación que se ha proferido en su contra; y por otro, implica para el Estado una sanción frente a su inactividad. ${ }^{7}$

Frente a lo anteriormente descrito, y ya entrando a la órbita del derecho ambiental Colombiano, se tiene que el artículo 10 de la ley 1333 de 2009 expresa; "Caducidad de la Acción. La acción sancionatoria ambiental caduca a los 20 años de haber sucedido el hecho u omisión generadora de la infracción. Si se tratara de un hecho u omisión sucesiva, el término empezará a correr desde el último día en que se haya generado el hecho o la omisión. Mientras las condiciones de violación de las normas o generadoras del daño persistan, podrá la acción interponerse en cualquier tiempo."

Es entonces este, el primer peldaño que debe superar el operador administrativo cuando va a realizar el análisis de la posibilidad de la persecución sancionatoria ambien-

\footnotetext{
Ver. Corte Constitucional. Sentencia del 26 de mayo de 2010. Magistrado Ponente: Gabriel Eduardo Mendoza Martelo. (Sentencia Número c-401 DE 2010), pág. 2. Copia tomada directamente de la Corporación. Ibídem
} 
tal sobre una persona natural o jurídica. Ahora bien, se debe tener en cuenta que si bien es cierto que la acción sancionatoria ambiental caduca a los 20 años de haber sucedido el hecho u omisión generadora de la infracción, no se debe olvidar que la norma trajo consigo los postulados de la responsabilidad civil extracontractual, al hacer referencia a las conductas consideradas infracciones de tracto sucesivo, las cuales no son más que la prolongación en el tiempo de la acción o violación normativa derivada de un mismo hecho, el cual genera un resultado negativo constante sobre los recursos naturales o el medio ambiente. Dichas infracciones de tracto sucesivo deben ser muy bien detalladas por el operador administrativo para no caer en impresiones que puedan vulnerar el principio del debido proceso administrativo al aperturar varios procesos sancionatorios ambientales teniendo en cuenta la generación de varios resultados o un resultado nocivo prolongado en el tiempo, cuando solo se debería instruir un único proceso sancionatorio con el agravante establecido en la norma procesal ambiental.

\section{Conclusiones}

A manera de conclusión se debe expresar que en Colombia es urgente que se plantee un debate sobre la ley 1333 de 2009, en búsqueda de una reforma y técnica de redacción legislativa adecuada que permita una doble garantía; por un lado del administrado o procesado y por otra parte de la misma autoridad ambiental o del operador administrativo ambiental.

En materia procesal ambiental, deben existir unos límites claros y definidos que garanticen que los poderes exorbitantes de la administración no perjudiquen a un ciudadano de forma injustificada e ilegal, o que tenga que cargar con cargas más pesadas que las que está obligado por mandato legal, por lo que en materia de impo- sición de sanciones por la comisión de infracciones a la normatividad ambiental vigente aún no se ha desarrollado una esquemática seria y profunda para ello por lo que es relevante la inclusión y adecuación de los criterios expresados desde la óptica de la teoría del delito y especialmente de la teoría finalista, lo cuales son punto de partida ineludible en una adecuación de la infracción ambiental, por lo que sus componentes como conducta, tipicidad, antijuridicidad y responsabilidad son elementos de aplicación actual y necesaria en el evento de estudiar y analizar la infracción en materia ambiental por parte de las autoridades administrativas que conforman el SINA (Sistema nacional ambiental) consagrado en la ley 99 de 1993.

Los operadores administrativos de las autoridades ambientales, en su gran mayoría, adolecen de un plan metodológico para efectos de motivación del acto administrativo sancionatorio, por lo que solamente toman como referente el hecho, la presunción de culpa o dolo y el sujeto, desconociendo elementos desarrollados en la dogmática del delito en materia penal, que bien se pueden utilizar en la infracción ambiental como la antijuridicidad, la tipicidad, la necesidad de la pena, la imputabilidad y demás elementos constitutivos del delito.

Este articulo debe servir como mecanismo metodológico de interpretación normativa por parte de los operadores administrativos ambientales en su diario vivir y en su quehacer jurídico e defensa del medio ambiente y de los recursos naturales entendiéndose que aunque los derechos ambientales son derechos superiores de los que depende la colectividad y por ende son titulares de su protección, tampoco puede ser justificación para la vulneración de derechos fundamentales de los procesados por infracciones ambientales.

\section{Referencias}

\section{Doctrina}

Cabanellas, G (1986) Diccionario Enciclopédico de Derecho Usual, T. I, Ed. Heliasta, Buenos Aires

Garro, Á y Arroyave, J (2011). La definición de infracción ambiental en la ley 1333 de 2009: ¿es contraria el principio de legalidad?, Ed. Universidad de Medellín.

González J (2006). Derecho ambiental colombiano, parte general. Ed, Universidad Externado de Colombia. 
Gutiérrez I La Responsabilidad Por El Daño Ambiental En Colombia. Disponible en http://www.google.com.co/url?sa=tErct=jE $q=\mathcal{E} e s r c=s \mathcal{E} s$ ource $=$ webE $c d=1 \mathcal{E} v e d=0 C C g Q F j A A \mathcal{E} u r l=h t t p \% 3 A \% 2 F \% 2 F w w w . p n u m a . o r g \% 2 F g o b e r n a n z a \% 2 F N o .5$ LaRe sponsabilidadporDa\%25F1oAmbiental.docEei=fU8U4HMKY2lsATZq4CwDgEusg=AFQjCNFTEkwMC7XKAygt0wnWF A9TYJr-3g

Henao, J (2003), ponencia; responsabilidad por daños al medio ambiente, Universidad Externado de Colombia. 2003

Iturregui Byrne, P (1997). Principios de Derecho Ambiental Internacional y Legislación Nacional (...). En: Foy Valencia, Pierre (Editor). Derecho y Ambiente.. Lima Perú. IDEA-PUCP

Muñoz Conde, F (1990). Teoría General del Delito. Ed. Temis. Bogotá 1990

Roxin, Claus (1976). Problemas básicos del derecho penal. Ed. Reus. Madrid. 1976

Varios Autores. (2008). 15 años de la Constitución ecológica de Colombia, Ed, Universidad Externado de Colombia.

Varios Autores. (2009) El daño ambiental, Bogotá. D. C. Ed, Universidad Externado de Colombia

Martín Mateo, R (1977). Tratado de derecho ambiental. Madrid. Instituto de estudios de la administración local.

Nieves, R (2010). Teoría del Delito y Práctica Penal - Reflexiones dogmáticas y mirada crítica, Pg. 7, Escuela nacional de ministerio público, Santo Domingo. Ed. Centenario S.A.

Welzel, H (1987). Derecho Penal Alemán. Ed. Jurídica de Chile. 12ª . Edición. Santiago.

\section{República de Colombia. Legislación}

La ley 99 de 1993

Ley 1333 de 2009

Decreto-ley 2811 de 1974

Ley 99 de 1993, y la Ley 165 de 1994

\section{República de Colombia. Jurisprudencia de la Corte Constitucional:}

Sentencia C-840/2001. Magistrado ponente: Jaime Araujo Rentería.

Sentencia C 181 de 2002 Magistrado ponente: Marco Gerardo Monroy Cabra.

Sentencia T-438 de 1992. Julio 1 de 1992. Magistrado ponente: Eduardo Cifuentes Muñoz.

Sentencia T-832/03. Pág. 6. Magistrado ponente:. Jaime Córdoba Triviño.

Sentencia T-415 de 2005. Magistrado ponente: Marco Gerardo Monroy Cabra.

Sentencia C-703 de 2010

Sentencia C-632/11 Magistrado Ponente: Gabriel Eduardo Mendoza Martelo Bogotá D.C., veinticuatro (24) de agosto de 2011. 